\title{
Research and analysis on the construction of e-commerce intelligent decision system of logistics enterprise
}

\author{
Yong Zhu \\ School of Economics \& Management \\ Chongqing Normal University \\ Chongqing, China \\ E-mail: zhuyong169@126.com
}

\author{
Shaowen Zhang \\ School of Economics \& Management, \\ Chongqing Normal University \\ Chongqing, China \\ E-mail: shaowen9223@163.com
}

\begin{abstract}
This article systematically analyses the requirements on e-business intelligent decision system of logistics enterprises and the technical path and method of constructing e-commerce intelligent decision-making system of logistics enterprise from the database system module, data mining system module, on-line analysis module and decision support system module. The construction of decision system has an important role in promoting the modern logistics enterprise to improve the rapid response ability to market with the Internet platform. Based on the operating mechanism of e-commerce intelligent decision-making system of logistics enterprise, the paper designs the operation platform structure of logistics enterprise e-commerce operation decision, so as to provide the concrete technology methods for logistics enterprise to promote roundly the construction of electronic commerce.
\end{abstract}

Keywords-electronic commerce; intelligent decision system; Operation platform

\section{INTRODUCTION}

By the use of logistics information, it is the core of modern logistics effectively integrating the logistics system resources with various technical means; the purpose is to improve the integral function and benefit of logistics system. Logistics enterprise e-commerce intelligent decision-making system arises based on the special mission; it is the intelligent stage that logistics information system integrates enterprise logistics with logistics system as the application background, for logistics decision makers of correct decision to provide support platform scientific. Studying and designing the system model not only theoretically lays the foundation for the development and utilization of logistics enterprise e-commerce intelligent decision system, but also has very important practical significance for speeding up the logistics enterprise information process.

Information age, logistics enterprise information is the inevitable requirement of improving the competitiveness, the specific performance is the commercialization of logistics information, the database and codify of logistics information collection, the electronic and computerized of logistics information processing, the standardization and real-time of logistics information passing, the digitization of logistics information storage, etc. This is a high-level application of the logistics automation and information. A large number of strategy and decision-making in logistics operation process, such as the determination of the inventory level, the choice of transportation (handling) path, the moving trajectory and operation control of automatic guide vehicle, the operation of automatic sorting machine, the decision support of logistics distribution center management and so on, all need the help of a lot of knowledge to solve it. In the process of logistics automation, logistics intelligent is an inevitable difficult technical problem. However expert system, robot and other related technologies have more mature research results in the world. In order to improve the level of modern logistics, the logistics intelligent decision system has become a new trend in the development of logistics under the e-commerce environment.

In e-commerce era, because the expansion of the company sales range, the change of the enterprise and business sales way and finally consumers' buying patterns, make door-to-door delivery business become an important service business, contribute to the rise of the logistics industry. The logistics industry is a industry which is able to provide complete logistics function service, transportation and distribution, warehousing, split charging and packaging, distribution processing and so on, to gain reward. It mainly includes the storage enterprise, transportation enterprise, loading and unloading handling, shipping enterprise, distribution processing, etc. Information, globalization, fictionalization and first-class service level, have become the goal that the e-commerce logistics enterprise pursuits.

\section{THE THEORY RESEARCH AND REVIEW}

In the e-commerce development initial period, many scholars carry on the corresponding research about the effects of material circulation. Haul Lee and Seungin Whang proposed that logistics distribution can realize the end distribution of online trading goods; it is the end of a link to complete the whole electronic business activities[1]. Kent N. Gourdin puts forward electronic business logistics service quality model, through analyzing the relationship between consumers and sellers in the model, shows the development process of the customer' dissatisfaction to electronic business logistics services, thinks that it can improve the satisfaction of consumer through the development of the normative logistics distribution quality control program[2]. Electronic business logistics service has become a hot topic of academic circles; Hertz and Alfredsson think that the third party logistics plays a very 
important role in the analysis of logistics mode [3].

When the logistics is important for the success of enterprise, the logistics management ability of enterprise is relatively low, enterprise adopt the third party logistics. The logistics is very important for the success of enterprise, and the enterprise has the very high logistics management ability, enterprise use mode of self-operations. The logistics is not so important for the success of enterprise, the logistics management ability of enterprise is weak, enterprise use the outsourcing logistics service.

Since 2008, Chinese e-commerce appears explosive growth. Efficient logistics system gradually becomes the security of e-commerce healthy operation. In recent years, the growth rate of Chinese electrical business is as high as $200 \%-300 \%$, but logistics growth is only $40 \%$, couldn't far keep up with the speed of electric business. Some scholars in China made a thorough research into how to improve the level of Chinese logistics e-commerce. On the electronic commerce logistics theory, in 2000, Yu Yi cheng gave detailed introduction on the concept of electronic commerce and electronic business logistics, had analyzed the generation function, classification of logistics and the features and trends of e-business, etc[4]. In 2012, Zhao Ai rong and Ren Xiao xia in the "the influence and countermeasures of electronic commerce to the logistics industry" pointed out that we must analyze and grasp in depth the influence of the electronic commerce to modern logistics industry, combine with the actual situation in China, in order to promote the rapid development of electronic business logistics industry [5].

On the analysis of logistics development mode, Cao Xiong bin analysis of the major logistics mode of the most common and most problematic B2C e-commerce in five kinds of electronic business activities forms, including B2B, $\mathrm{B} 2 \mathrm{C}$ and $\mathrm{C} 2 \mathrm{C}, \mathrm{B} 2 \mathrm{G} \mathrm{C} 2 \mathrm{G}[6]$. Zhang $\mathrm{Ru}$ yun analysis the causes and conditions of outsourcing self-supporting in the change of domestic electric business logistics mode[7].

But seen from domestic and international relevant research, the research about the construction and application of logistics enterprise electronic commerce decision-making system is still less, this thesis researches and analyzes in depth logistics enterprise electronic commerce intelligent decision system based on the current situation, tries to construct logistics enterprise electronic commerce decision-making system and application platform accord with Chinese national condition.

\section{INTELLIGENT DECISION-MAKING SYSTEM}

Electronic business intelligence system is consists of data warehouse, query statements, data analysis, data mining, data backup and restore, in order to help enterprise decision. Through the customer search and the analysis of database or data warehouse, it looks for the key factors influencing the operational activities of enterprise, and ultimately helps users to make better and more reasonable decision. As to logistics enterprise, the design of the electronic business intelligent decision-making system model must consider the demand of enterprise top managers, department supervisor, information manager and information analysis, so that decision makers can consider all factors for scientific decision-making. But seen from the problems of Chinese logistics enterprise at present, there are problems in the construction of electronic commerce: low information level, the lack of the intelligent platform to analyze historical data and the mass information, enterprise management decision lack of scientific basis, The lack of a set of agile transport distribution scheduling system; The lack of good inventory decision system, etc, which have seriously restricted the pace of Chinese logistics enterprise to the international logistics market.

(1) Functions of basic enterprise information management, on the one hand enterprise information management can provide enterprises with electronic information management platform to realize the information of enterprise management; on the other hand it is responsible for collecting all kinds information of logistics enterprise, to provide the necessary data for the establishment of enterprise decision support system, and the establishment of electronic business intelligent decision-making system also depends on collected data of enterprise information management module, such as: the customer information management data, warehouse inventory management data, transportation and distribution management data, financial management data, etc.

(2) Senior decision-making functions, such as: customer value analysis, inventory optimization decision-making, location arrangement, intelligent distribution and so on.

Logistics enterprise decision-making problem has multiple layers of target system, complicated and agile constraint conditions, indeterminable surrounding environment beforehand, the logistics enterprise electronic commerce intelligent decision-making system should have two set of knowledge processing or the ability to complete certain thinking activities, in order to solve complicated decision problem, and to inspire and guide the user according to the characteristics of the problem to solve them. On unstructured problems, it should be able to use expert reasoning knowledge to solve, achieve finally the purpose to assist decision makers to make the high quality decision.

\section{FUNCTION STRUCTURE DESIGN OF INTELLIGENT DECISION-MAKING SYSTEM}

Logistics enterprise electronic commerce intelligent decision-making system is mainly composed of business system module, data warehouse system module, data mining system module, on-line analysis module and decision support system module, as shown in Figure 1. 


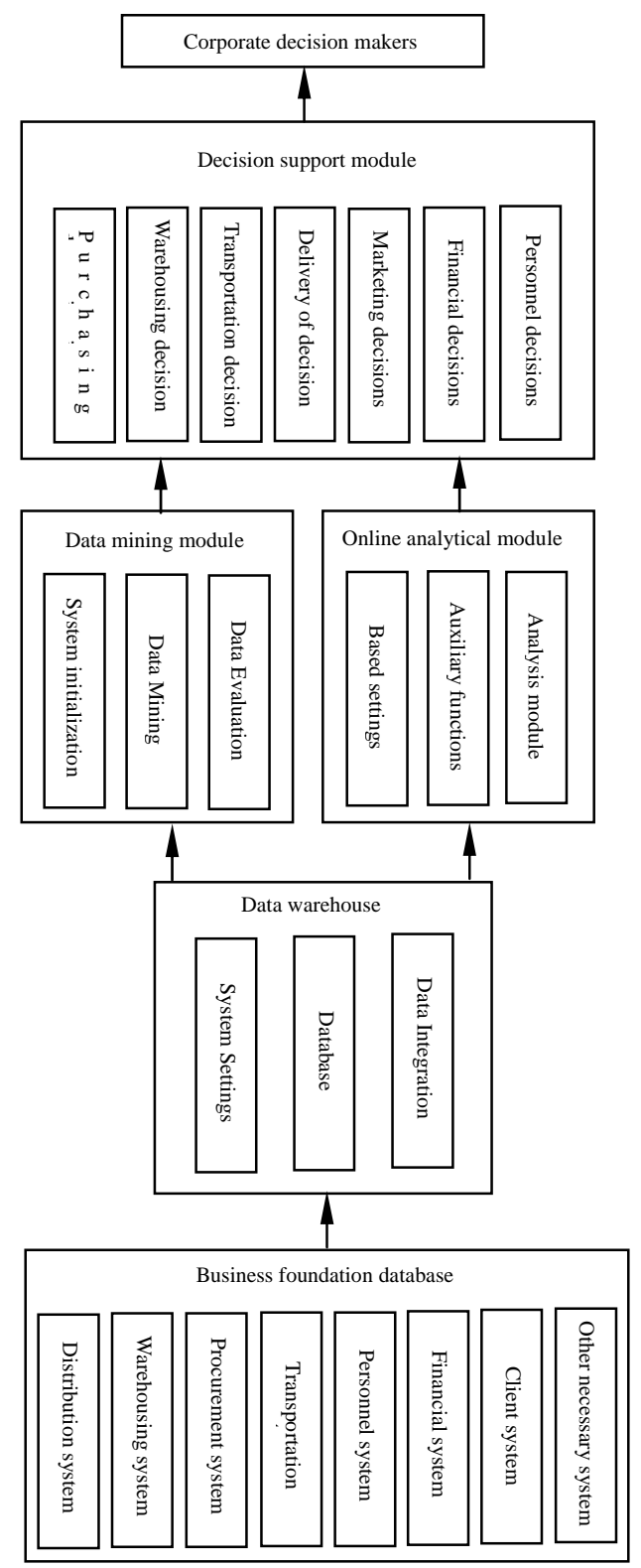

Fig.1 logistics enterprise electronic commerce intelligent decision model framework

The using of data mining module base on artificial intelligence, machine learning, statistics analysis technology, applying data mining analysis method, such as association rules analysis, sequence mode analysis, clustering/discriminant analysis, artificial neural network, digging out potential mode, law or relationship from a large number of data, to help enterprise policymakers adjust market strategy, predict customer behavior, reduce the risk and make the right decision. Through the establishment of various logistics decision model (vehicle route model, network logistics model, distribution set model, facility location model and global system. positioning system model, etc) to realize the interactive analysis of the logistics business, to provide a reasonable solution for integrated logistics operation. Finally, combined with on-line analytical processing (OLAP) module, transforming out the information which users can understand from current and historical data.

This information can truly reflect the dimensions characteristics of data and help analysis personnel from various angles to visit and analyze data quickly, consistent, interactively, so that managers can understand more the data deeply. The key to on-line analysis module is the multidimensional analysis of data warehouse data. Multidimensional analysis refers to analysis action, such as taking section, cutting into parts, grounding up rotation to data organized through various multidimensional form, in order to analyze data, to enable the end user can observe data in the database from many angles, so as to further understand the data contained information, connotation. OLAP system function mainly consists of two parts: to provide information service for the customers and provide statistical analysis for enterprise itself, this also is the basis of determining data warehouse theme

\section{LOGISTICS AND ELECTRONIC BUSINESS OPERATION DECISION PLATFORM ARCHITECTURE}

Logistics and electronic business operation decision platform is a comprehensive logistics and purchasing online e-commerce platform, including order online, offline distribution, cost settlement and decision support

The whole system platform is made up of five, parts composition: website platform portal, business information portal, decision support portal, logistics distribution portal, and fund settlement portal, as shown in Figure 2.

Through logistics and electronic operation decision Platform we can minimize inventory and funds occupation, transform traditional goods flow based operation into information flow based operation. Using real-time trading information to reasonably allocate distribution mode and production, inventory mechanism, maximize the efficiency of fund flow.

Logistics and electronic business operation decision platform is a fully modular software system platform with the decision-making intelligence as the core and the information as the guide, all the data transmission between the module use encryption mechanisms, independent security gateway is appended to bank payment system. Member users use the HTTPS encryption access, all management and configuration are based on WEB graphical management interface, it is easy to operate and maintain by administrator. Distributable multiple user permissions, limited module, specific function and the scope of the operation support system accident interrupt, single point interrupt, breakpoint automatic startup recovery function, to ensure that no one supervision automatic operation, the system support seamless cluster expansion ability, it can automatically load balance for the website group management.

For any hardware system downtime including database server, HA technology will not stop access services. 
enterprise electronic business decisions. But enterprise decision will involved in the field of psychology more.

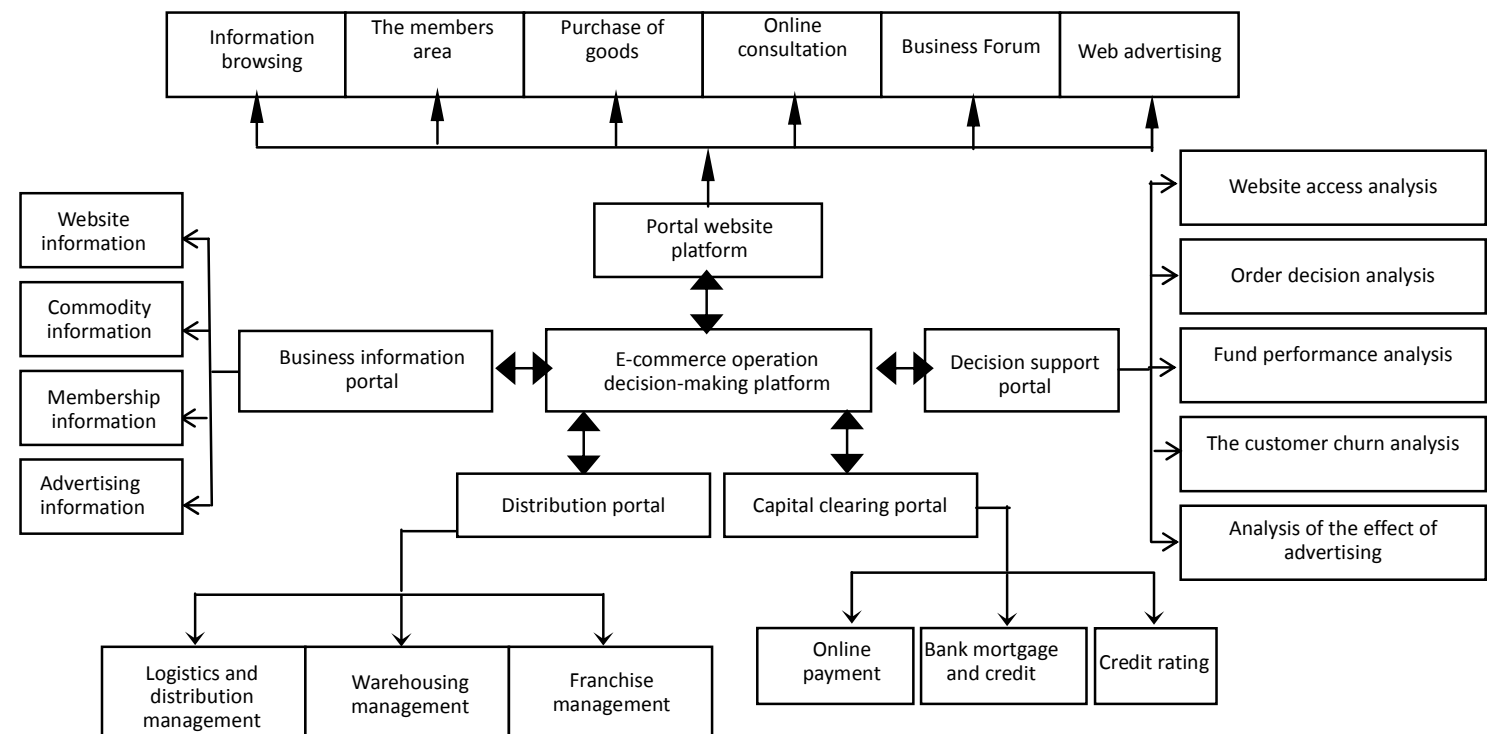

Figure 2. Logistics and electronic business operation decision platform

\section{CONCLUSION}

Decision Support System (DSS) is a user-oriented interaction system developed in the early 1970s. The traditional decision support system is composed of man-machine interface, database, the model base three subsystems and their interfaces between them, the main purpose is to support half structured and unstructured decision-making problems, in order to improve decision-making efficiency. Intelligent Decision Support System (IDSS) the paper proposed is the integrate of expert system and decision support system, can perform qualitative knowledge reasoning, quantitative model calculation, a large number of data processing.

The recent research on Decision Support System is further tend to intelligence, human nature, through analyzing the massive data, can provide correct guidance for enterprise managers' scientific decision. The development of Internet technology and the emergence of electronic business have changed humans' opinions. actual behavior for what is trading and how to operate, etc, and then make economic development prospects present an networking information new situation, also make the enterprises' decision support needs are more widespread and strong. In the paper, the Decision Support System has already considered the ubiquitous network transaction mode, and integrate technology and transaction mode from the point of view of the interdisciplinary.

The integration not only includes the integration of design language and the recommendation algorithm of the existing different Decision Support System, but also the integration of design framework of different decision support system of different transaction mode. At present, China's Decision Support System research mainly focused on the method. However, the article applies it to logistics
Future research can combine consumer preference, cognitive, performance, satisfaction psychology concepts with Decision Support System, so as to provide more support for logistics enterprise electronic business application design.

\section{REFERENCES}

[1] Haul Lee, Seungin Whangm Winning the last mile of E Commence, 2002.

[2] Kent N Gourdin, Global Logistics Management - A Competitive Advantage for the New Millennium, 2001.

[3] Hertz S, Alfredsson M. Strategic Development of Third Party Logistics Providers [J]. Industrial Marketing Management, 2002, 32(2).

[4] Haul Lee, Seungin Whangm Winning the last mile of E- Commence, 2002.

[5] Kent N Gourdin, Global Logistics Management A Competitive Advantage for the New Millennium, 2001.

[6] Hertz S, Alfredsson M. Strategic Development of Third Party Logistics Providers[J]. Industrial Marketing Management, 2002, 32(2).

[7] Ronald H. Ballow, Business Logistics Management, Prentice - Hall International Inc. 4th, 1999. 